\title{
Key Roles of Cysteine Protease in Different Plant Pathosystem
}

\author{
Marjohn Niño", Joonki Kim", Hye Jung Lee ${ }^{1}$, Sailila E. Abdula,2, Ill Sup Nou ${ }^{3}$, Yong-Gu Cho ${ }^{1}$ * \\ ${ }^{1}$ Department of Crop Science, Chungbuk National University, Cheongju 361-763, Republic of Korea \\ ${ }^{2}$ Current Address, Philippine Rice Research Institute-Midsayap, North Cotabato 9410, Philippines \\ ${ }^{3}$ Department of Horticulture, Sunchon National University, Sunchon 540-742, Republic of Korea
}

\begin{abstract}
Cysteine protease is one of the well-studied proteolytic enzymes in plants. This class of protease has been implicated in various physiological aspects of developmental stages in plants including seed germination, senescence, and disease immunity. A handful of studies assign plants cysteine protease in different molecular battlefield under a few selected pathosystems, and initially extricate complex molecular mechanism of resistance. Interestingly, the same type of proteases released by pathogens have been demonstrated to play a crucial role in establishing disease infection in plants. Most of which target resistance proteins resulting either in an access to the hosts biochemical loot or cascades of signals for defense. As means of enabling and disabling host immunity, this class of protease is subject to diversifying selection, which is an intriguing outcome under natural host pathosystem. This paper summar izes the key roles of cysteine proteases in a few selected plant pathosystems.
\end{abstract}

Keywords Cysteine protease, Disease immunity, Diversifying selection, Host-effector interaction, Phytopathogen, Plant pathosystem

\section{INTRODUCTION}

Cysteine proteases activity comprises majority of the proteolytic activities in plants. It shares approximately $30 \%$ of total proteolysis in mature non-senescing organs, and in some cases rises to $90 \%$ in response to stimuli (Grudkowska and Zagdanska 2004). Papain-like cysteine protease (PLCP) is equipped with $\mathrm{N}$-terminal auto-inhibitory domain covering the substrate binding groove which needs to be removed proteolytically for activation (Taylor et al. 1995). Cysteine proteases use catalytic cysteine residue as a nucleophile to cleave bonds of protein substrates (Shindo and van der Hoorn 2008) which results in an intermediate state where the enzyme is covalently attached to the substrate (van der Hoorn et al. 2004). Subsequent hydrolysis cleaves the peptide bond and releases the protease (Powers et al. 2002). The catalytic cysteine (C), which is responsible in binding with the substrate, is situated right in the middle of a cleft as part of a catalytic triad including histidine $(\mathrm{H})$, and asparagine (N) (Drenth et al. 1971; Shindo and van der Hoorn 2008). Aside from catalytic residues, the protease domain also contains two disulfide bridges (SS) (Shindo and van der Hoorn 2008).

Apparently, plants utilize the same proteolytic machinery to halt pathogen invasion. There have been reports on papain-like cysteine proteases acting as inhibitory agent against fungus, bacteria, oomycete and nematode such as Rcr3 (Krüger et al. 2002), PIP1 (Tian et al. 2007), RD19 (Bernoux et al. 2008), RD21 (Shindo et al. 2012), C14 (Kaschani et al. 2010) and Cath B (Gilroy et al. 2007). Each confers unique participation in the induction of host immunity which is evident in the specific interactions with the effectors, involvement in a specific molecular battlefield, and the resulting immunity threshold. Interactions of proteases with their substrates and inhibitors, to some extent provokes selection of the counteracting inhibitors, non-cleavable substrates and other means to evade proteolysis (Shindo and van der Hoorn 2008) which lead to evolutionary diversification.

Interestingly, pathogens are also engaged in proteolysis which either leads to repression or activation of plant defense system. A substantial evidence revealed Pseudomonas

Received June 24, 2014; Revised June 26, 2014; Accepted June 27, 2014; Published June 30, 2014

*Corresponding author Yong-Gu Cho, ygcho@cbnu.ac.kr, Tel: +82-43-261-2514, Fax: +82-43-273-2242 
syringae as among those which produce more than one family type of cysteine protease (CP) (Axtell and Staskawicz 2003; Mackey et al. 2003; Shao et al. 2003; Lopez-Solanilla et al. 2004; Coaker et al. 2005). Some of the reported microbial cysteine proteases are channeled into the apoplasts while others are directly translocated to the plant cytoplasm. Like other classes of effector, activities of PLCP effector also perturb key host resistance protein target.

This review focuses on some members of clans CA and $\mathrm{CE}$ that are related to plant disease and resistance. In particular, this paper shows the diverse functions of selected PLCPs such as Cath B, PIP1, Rcr3, RD19, RD21, PopP1, AvrPphB, and AvrRPT2. Moreover, this paper describes the nuclear trafficking incidence of PLCP during plant-pathogen interaction, and shows extent of evolutionary diversification of PLCP caused by selection pressure.

\section{Major clan of cysteine proteases implicated to disease immunity}

There are at least two important clans of cysteine proteases implicated to play crucial role in plant diseases and resistance, these include CA and CE. Both contain proteases with a papain-like fold (van der Hoorn 2008). MEROPS database showed that papain-like cysteine proteases (PLCPs) classified under CA are the most abundant in nature being present in numerous species of bacteria, archea, protozoa, fungi, plants, animals, and viruses (Rawlings et al. 2014). Most members of this clan are pre-proteases containing a signal sequence, an autoinhibitory prodomain, and a mature protease domain (van der Hoorn et al. 2004). To date, this clan comprises 32 families, four of which were indicated to be related to plant diseases and resistance including $\mathrm{C} 1$ (mainly host plants), C6, C58, and C70 (mainly pathogenic microbes) (Rawlings et al. 2014). The $\mathrm{C} 1$ family is subdivided into $\mathrm{C} 1 \mathrm{~A}$, an extracytoplasmic PLCPs that possess disulfide bridges and accumulate in the vesicles, vacuole, and apoplast, and the subfamily C1B which comprises cytoplasmic PLCPs (subfamily C1B) (Rawlings et al. 2006; Shindo and van der Hoorn 2008). The MEROPS database has indicated 169 plants species with CP assigned to this family (Rawlings et al. 2014). Of which, 11 species were shown to contain more than 30 homologues in their genome including Glycine max, rice,
Arabidopsis lyrata and Zea mays, among others.

The other three families under clan CA implicated to plant disease and immunity represent the key effectors important in initiating disease in a specific host plant. The C6 family contains cysteine endopeptidases of RNA viruses such as potato virus Y-type helper component peptidase (potato virus $\mathrm{Y}$ ) and barley yellow mosaic virustype helper component peptidase (Rawlings et al. 2014). The only known peptidase activity of this group is the cleavage at its own C-terminus, at a preferred sequence site -Tyr-Xaa-Gly+Gly-, which releases it from the viral polyprotein (Carrington and Herndon 1992; Rawlings et al. 2014). In the case of C58 family, endopeptidases members act as transamidases, which attach a lipid moiety to the exposed N-terminus of the substrate. This group is further classified to two subfamilies, C58A and C58B, both solely distributed among species of bacteria (Rawlings et al. 2014). The AvrPphB of Pseudomonas syringae is the only member of C58B family and has been implicated to initiate disease in beans (Shao and Dixon 2004). For family C70, putative members are mainly of bacterial origin showing close homology with AvrRpt2 peptidase in Pseudomonas syringae (Rawlings et al. 2014). AvrRpt2 has been demonstrated to induce self-cleavage as means of autoactivation, and inhibition of RIN4 protein in the host cell (Axtell et al. 2003). These activities contribute to the virulence of Pseudomonas syringae.

Several peptidases in clan CE exhibit preferential cleavage after diglycine due to the presence of aromatic residue such as tryptophan which follows the catalytic histidine in the sequence (Golubtsov et al. 2006; Rawlings et al. 2014). Proteases in this clan are characterized by a cysteine nucleophile and a catalytic core composed of three amino-acid residues, $\mathrm{H} / \mathrm{E} / \mathrm{C}$ or H/D/C (Hotson and Mudgett 2004). As mentioned in MEROPS database, members of $\mathrm{CE}$ contain two structural subdomains with the active site in the middle. One subdomain carries the active site His and Glu (or Asp) and the second subdomain carries the catalytic Cys. CE peptidases structure resembles clan CA except for the reversed order of subdomains. Peptidase family C55 comprises bacterial effector peptidases with restricted specificity, three of which are key factors affecting economically important crops. The members include PopP1 
(Ralstonia solanacearum), AvrXv4 (Xanthomonas sp.) and HopZ1 protein (Pseudomonas syringae) (Rawlings et al. 2014).

\section{Cysteine protease-mediated resistance in different pathosystem}

Plants developed a variety of perception system such as pattern recognition receptors (PRRs) and resistance (R) gene products alerting the defense signals once perturbed by activities of pathogen. Classical definition of plant immunity solely involves ligand-receptor model indicating products of $\mathrm{R}$ genes as receptors that directly interact with the products of Avr genes (Keen 1990). However, in some $\mathrm{R}-\mathrm{Avr}$ combinations, direct physical interactions are rather an isolated case as perception is often shown as indirect (van der Biezen and Jones 1998; Dangl and Jones 2001).

Cysteine proteases, particularly the PLCPs have been reported to play an important role either in pathogen perception taking the role as a guardee, and in disease resistance signaling (van der Hoorn 2008). Cysteine proteases are also involved in the programmed cell death (PCD) induced by developmental cues or pathogens (Solomon et al. 1999). The following are selected members of the PLCP acting in plant disease and resistance (Table 1).

\section{Cath B}

Hypersensitive response (HR) is a form of programmed cell death (PCD) that occurs at the site of pathogen entry and is mostly accompanied by the induction of defense responses to wall-off the pathogen (Lam et al. 2001). Using virus-induced gene silencing, Gilroy et al. (2007) demonstrated the involvement of cathepsin $B$ in the plant disease resistance hypersensitive response. Effects of CathBsilencing to HR were demonstrated in two different non-host pathosystem involving $N$. benthamiana infiltrated with Erwinia amylovora (causal pathogen of fireblight in apple and pears) and Pseudomonas syringae pv. tomato (Pst) DC3000 (causal agent of bacterial speck in tomato). Both Eam- and Pst-mediated HR in TRV::NbCathB plants diminished even at the lower inoculum concentration $\left(10^{6}\right.$ $\mathrm{cfu} \mathrm{ml}^{-1}$ ) and the onset was delayed for $72 \mathrm{hpi}$ at the higher concentration $\left(10^{7} \mathrm{cfu} \mathrm{ml}^{-1}\right)$. This suppression leads to the accumulation of higher viable cells (an eight-fold increased recovery of Eam and a five-fold increase recovery of $P s t$ ) in virus-induced gene silencing (VIGS) plants than in control plants transformed with TRV ::gfp. Using temporal expression analysis, regulation of the HR by $C a t h B$ was validated wherein, expression of HR gene marker $H_{s} 203$ was suppressed in VIGS plants. Interestingly, CathB also functions in HR triggered by a specific gene-for-gene

Table 1. Selected papain-like cysteine proteases implicated to play in plant disease and immunity.

\begin{tabular}{|c|c|c|c|c|}
\hline Protease & Source & Affinity & Function & Reference \\
\hline Cath $B$ & N. benthamiana & $\mathrm{C} 1 \mathrm{~A}$ & $\begin{array}{l}\text { Regulates HR; involved in nonhost and } \\
\text { host-specific disease resistance }\end{array}$ & Gilroy et al. 2007 \\
\hline$R c R 3$ & S. lycopersicon & $\mathrm{C} 1 \mathrm{~A}$ & $\begin{array}{l}\text { Common virulence target of } C \text {. fulvum } A v r 2 \text { and } G \text {. } \\
\text { rostochiensis VAP1 }\end{array}$ & $\begin{array}{l}\text { Krüger et al. 2002; } \\
\text { Lozano-Torres et al. } 2012\end{array}$ \\
\hline$P I P 1$ & S. lycopersicon & $\mathrm{C} 1 \mathrm{~A}$ & $\begin{array}{l}\text { A PR protein and a virulence target of } P \text {. infestans } \\
E P I C 2 B\end{array}$ & Tian et al. 2007 \\
\hline$R D 19$ & A. thaliana & $\mathrm{C} 1 \mathrm{~A}$ & Virulence target of $R$. solanacearum PopP2 & Bernoux et al. 2008 \\
\hline$R D 21$ & A. thaliana & $\mathrm{C} 1 \mathrm{~A}$ & $\begin{array}{l}\text { Renders protection against necrotrophic pathogen } \\
\text { Botrytis cinerea }\end{array}$ & Shindo et al. 2012 \\
\hline PopPl & R. solanacearum & $\mathrm{C} 55$ & $\begin{array}{l}\text { Encodes Avr protein which modulates } \\
\text { aggressiveness to the host }\end{array}$ & Lavie et al. 2002 \\
\hline$A v r P p h B$ & P. syringae & $\mathrm{C} 58$ & $\begin{array}{l}\text { Inhibits PBS1 kinase and induces HR in } \\
\text { Arabidopsis }\end{array}$ & Shao et al. 2003 \\
\hline AvrRpt2 & P. syringae & $\mathrm{C} 70$ & $\begin{array}{l}\text { Activates RPS } 2 \text {-mediated resistance in tomato by } \\
\text { inhibiting RIN4 }\end{array}$ & Mackey et al. 2002 \\
\hline
\end{tabular}


interaction. The HR in TRV::gfp coexpressed with potato $R 3 a$ and Phytophthora infestans Avr3a was abolished in TRV::NbCathB plants. But such suppression was not observed under Clasdosporium fulvum Avr4- and tomato $C f-4$-mediated HR. The specificity of action suggests that Cath $B$ is not an obligatory component for all PCD triggered during disease resistance. Detailed mechanism of resistance remains limited, nevertheless, these findings suggest the dynamic role of Cath $B$, being an important component of defense both in non-host and in specific gene-for-gene disease resistance. A detailed information was reported by Gilroy et al. 2007.

\section{Rcr3}

Recently, it has been shown that the $C f-2$ mediates dual resistance in tomato involving two different pathogens, fungus and nematode, utilizing a common virulence target cysteine protease (Lozano-Torres et al. 2012). In the first report, a trans-membrane protein with extracellular leucinerich repeats (LRRs) and short (23 to 36 amino acid) cytoplasmic domains-encoding $C f$-genes confer resistance to the fungus Cladosporium fulvum in association with the required for Cladosporium resistance 3 (Rcr3) (Fig. 1B) (Dang and Jones 2001; Dixon et al. 2000; Krüger et al. 2002). Rcr3 encodes an apoplast-secreted papain-like cysteine protease of 344 amino acids with proven proteolytic activity (van der Hoorn 2008). Avr2 on the other hand encodes a secreted, cysteine-rich protein (Dixon et al. 1996). Inoculation of tomato with C. fulvum results in a rapid elevation of Rcr 3 transcripts especially in incompatible (resistant) interactions, resembling a pathogenesis-related genes response (de Wit et al. 1986; Krüger et al. 2002). The resistance response involves HR at the site of inoculation thereby limiting further pathogen invasion (van der Hoorn 2008). Since $R c r 3$ is a secreted cysteine protease and has a specific role in $C f$-2-mediated resistance, it was thought to function upstream of $C f-2$ and was considered as obligatory component required for $C f$-2-mediated fungal resistance (Krüger et al. 2002; Rooney et al. 2005). It was proposed that inhibition of $R c r 3$ by $A v r 2$ induces a conformational change in Rcr3 resulting in Rcr3-Avr2 complex which activates $C f$-2-mediated HR (Rooney et al. 2005; Bernoux et al. 2008). The mechanism pattern is consistent with the guard theory where in $C f-2$ guards $R c r 3$ and triggers defense response upon perception of an $R c r 3 / A v r 2$ complex. A detailed information was reported by Krüger et al. 2002.

Interestingly, a recent study conducted by Lozano-Torres et al. (2012) demonstrates that the $C f$-2-mediated resistance against the nematode Globodera rostochiensis requires the same target cysteine protease inhibited by the $A v r 2$ from $C$. fulvum (Fig. 1C). As the obligate dormant period of the potato cyst nematode G. rostochiensis culminates and as soon as the nematode begins to hatch from the egg, its effectors are activated and are ready for translocation to the apoplast and cytoplasm of host cells through the stylet. Using liquid chromatography-mass spectrophotometry, the venom allergen-like effector protein, VAP1, was shown to be secreted to the apoplast of host cells alongside plant cell wall modifying proteins. Based on the yeast twohybrid analysis which used Gr-VAP1 as bait, this effector was found to interact with the apoplastic cysteine protease $R c r 3^{p i m}$ of tomato. A subsequent co-immunoprecipitation assay asserts the specificity of the Gr-VAP1 and $R c r 3^{\text {pim }}$ interaction. Disease screening for resistance to $G$. rostochiensis revealed a $68 \%$ lower infection in $C f-2 / R c r 3^{\text {pim }}$ compared to $C f-O / R c r 3-3$ and $C f-2 / r c r 3-3$ indicating that both $c f-2$ and $R c r 3$ are necessary for resistance to the cyst nematode in tomato. Further, transient expression of Gr-VAP1 in the leaves of tomato triggers a $C f-2 / R c r 3^{\text {pim }}$-dependent programmed cell death. A detailed information was reported by LozanoTorres et al. 2012.

\section{PIP1}

Phytophthora inhibited protease 1 (PIP1), a papain-like extracellular cysteine protease, is closely related to the tomato cysteine protease $R c r 3$ in the C1A-5 group (Tian et al. 2007). Genetic mapping analysis of the two genes in a population derived from a cross between tomato cv. Sun1642 and S. pimpinellifolium accession LA1589 reveals tight linkage of PIP1 and Rcr3 near marker TG14 on chromosome 2 (van der Knaap and Tanksley 2001; Tian et al. 2007). The oomycete $P$. infestans has been reported to induce late blight in tomato and potato (Birch and Whisson 2001; Smart and Fry 2001; Ristaino 2002). Motif searches 
of $P$. infestans unigenes revealed a family of cystatin-like protease inhibitors, two of which EPIC1 and EPIC2 were upregulated during infection of tomato (Tian et al. 2007). The Epic-PIP1 interaction was investigated by Tian et al. (2007). By performing coimmunoprecipitation assay on tomato intercellular fluids isolated from two different genotypes: $R c r 3^{\text {pim }}$ and $r c r 3$ mutant, both incubated with rEPICs, it was found that EPIC2B interacts with PIP1 (Fig. 1E). Confirmation of EPIC2B-PIP1 interaction was done through western blot analysis of the intercellular fluids of PIP1-transiently transformed $N$. benthamiana. Results of cysteine protease activity profiling assay corroborated previous findings that EPIC2B inhibits the intercellularsecreted PIP1, a functional cysteine protease. Previously, PIP1 was shown to correlate with a large number of SA-induced PR protein genes including PR1, PR2, PR3, and PR7 (Zhao et al. 2003). Indeed, upregulation of PIPI was observed during treatment with SA analog BTH implying that the gene is a PR protein. A detailed information was reported by Tian et al. 2007.

\section{RD19}

Most Gram-negative bacteria utilize type-III secretion system either to suppress basal defense or initiate effectortriggered immunity. This group of effectors is mostly translocated directly to the host cell cytoplasm (Jones and Dangl 2006). Ralstonia solanacearum is a soil-borne proteobacterium known to cause wilts especially to Solanaceous plants (Hayward 1991). R. solanacearum encodes Pseudomonas outer protein P2 (PopP2) which confers a specific immunity response in Arabidopsis mediated by RESISTANT TO R. SOLANACEARUM I-R (RRS1-R), its cognate $\mathrm{R}$ protein (Fig. 1A) (Deslandes et al. 2003). PopP2 is a cysteine protease effector and a member of YopJ/ AvrRxv protein group under C55 peptidase family of clan

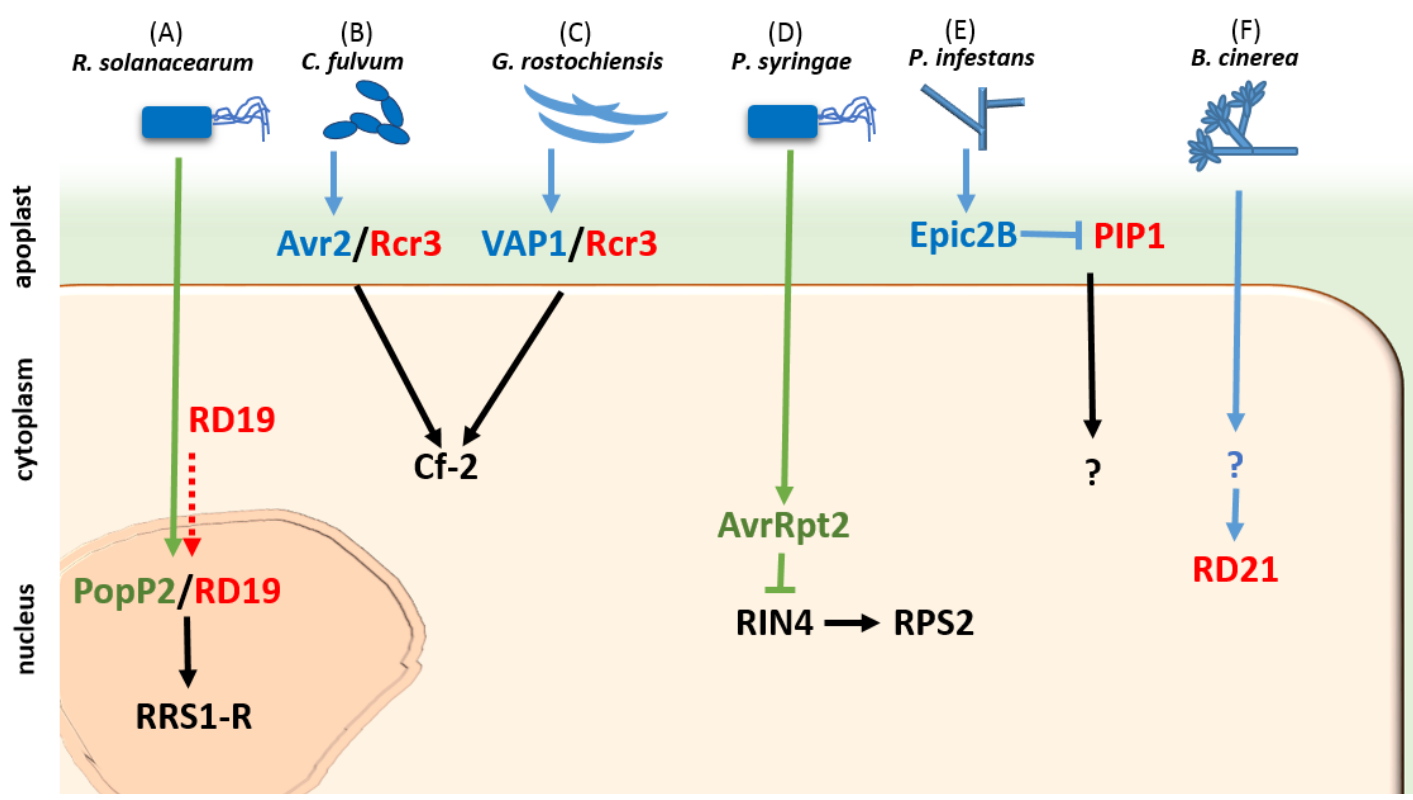

Fig. 1. Cellular localization of PLCPs during host-pathogen interaction in six selected pathosystems. Genes in red are host's PLCP, the green ones are PLCPs secreted by pathogen, the blue ones are non-cysteine protease effectors that interact with host's PLCP, and the black ones are host's resistance proteins. (A) Secretion of PopP2 to host's nucleus recruits RD19 from lytic vacuoles and form nuclear complex which activates RRS1-R mediated resistance (Deslandes and Rivas 2011); (B,C) C. fulvum Avr2 and G. rostochiensis VAP1 target the same protein, Rcr3, in the apoplast to form complex ligand which activates common R protein Cf-2 (Shindo and van der Hoorn 2008); (D) AvrRpt2, a PLCP secreted by P. syringae, inhibits RIN4 and activates RPS2 (Mackey et al. 2003); (E) The Epic2B effector delivered by $P$. infestans targets and inhibits PIP1, a tomato PLCP secreted in apoplast (Shindo and van der Hoorn 2008); and (F) B. cinerea, a necrotrophic fungus activates RD21, a PLCP localized in vacuole (Shindo et al. 2012). 
CE (Barret and Rawlings 2001). RRS1-R, on the other hand, is an atypical resistance protein which contains Toll/Interleukin 1 receptor (TIR)-NBS-LRR domain and C-terminal WRKY domain (Deslandes et al. 2002; Eulgem and Somssich 2007). To investigate the components of RRS1-R/PopP2-mediated disease resistance signaling, Bernoux et al. (2008) performed a yeast two-hybrid with PopP2 as bait which led to the identification of RESPONSIVE TO DEHYDRATION19 (RD19), a predicted PLCP of subfamily C1A (Rawlings et al. 2014). Using gene knockout strategy, involvement of $R D 19$ in $R R S 1-R$-mediated resistance signaling was studied. Disease screening test involving mutant line ( $r d 19 / R R S 1-R)$ showed compromised resistance wherein disease symptoms correlated with an increase of bacterial growth in the mutant. Confirmation of this function was done through genetic complementation of the mutant lines which resulted in a regained resistance phenotype. Accumulation of $R D 19$ transcripts was found to increase after inoculation with $R$. solanacearum. The quantitative noninvasive FLIM approach reveals the physical association of RD19 with PopP2. Interestingly, it fails to show interaction between RRS1-R and RD19. A detailed information was reported by Bernoux et al. 2008.

\section{RD21}

The role of C14-like protease in the model pathosystem Hyaloperonospora arabidopsis (Hpa) and Arabidopsis thaliana has been investigated. Hpa is an obligate biotrophic oomycete pathogen causing downy mildew in Arabidopsis. It proliferates in the leaf apoplast and uses haustoria to gain access for nutrition in the parenchyma cells (Coates and Beynon 2010). Shindo et al. (2012) identified RD21 (At1g47128), the closest ortholog of tomato C14 with 58\% prodomain homology, $76 \%$ protease domain similarity, and are $61 \%$ alike in granulin domain. Accordingly, a search for EPIC orthologs from Hpa was done and three EPIC-like proteins, HpaEPIC-A, -B and $-\mathrm{C}$ were identified. Phylogenetic analysis determined HpaEPIC1C-B and -C, the most likely ortholog of PinfEPIC1 and -2B, which were then selected for the subsequent analysis. To determine the function of the gene, knockout lines were generated. Subsequent disease evaluation shows that the gene knockout does not affect interactions with either virulent or avirulent strains of Hpa. To demonstrate the proposed role of the gene during incompatible interactions, another pathogen $P$. syringae was used to infect the mutant line, and yet the treatment failed to show changes in the phenotypic response compared with the wild type. The $r d 21$ mutant was tested against the pathogen Botrytis cinerea and surprisingly it exhibits an increased susceptibility suggesting its specific role in immunity against necrotrophic fungal pathogen (Fig. 1F). This sensitivity response of the host proteases is in consistent with the fact that the $B$. cinerea genome does not encode PLCPs inhibitor protein (Rawling et al. 2010). A detailed information was reported by Shindo et al. 2012.

\section{Cysteine protease secreted by phytopathogen}

Pathogens have developed arsenal effectors that target host defense either by inhibiting or manipulating the receptors or host resistance gene products. Phytopathogenic bacteria use the type-III secretion system (TTSS) to directly deliver effector proteins into the plant cells presumably to initiate disease infection (Cornelis and Gijsegem 2000). These effector proteins are host-specific and trigger immunity in plants harboring a corresponding resistance gene (Keen 1990). Most Gram-negative phytobacteria contain TTSS that are encoded by hrp (hypersensitive response and pathogenicity) genes, proving their crucial role in mediating diverse plant-bacteria interactions (Lindgren et al. 1986; Alfano and Collmer 2004; He et al. 2004; Buttner and Bonas 2006). Previously, bacterial cysteine proteases have been shown to play important role both in compatible and incompatible host-gene interaction by targeting specific plant substrates (Hotson and Mudgett 2004). Most phytopathogenic bacterial cysteine proteases are classified to two major clans, CA and CE (Rawlings et al. 2014). The following are examples of cysteine protease TTSS in phytobacteria.

\section{PopP1}

Pseudomonas outer protein P1 (PopP1), a cysteine protease secreted by Ralstonia solanearum, is closely related with the YOPP/YOPJ pathogenicity factors from human pathogen Yersinia (Orth et al. 2000; Orth 2002). 
PopPl encodes a $41-\mathrm{kDa}$ protein and possesses the conserved amino acid triad characteristics for cysteine proteases (Orth et al. 2000). Questions regarding its function in plant-bacteria interaction were addressed by Lavie et al. (2002). The loss-of-function analysis revealed that $P o p P 1$ acts as a host-specificity factor encoding an Avr protein which modulates aggressiveness of the bacterium toward the host plant. Modulation of virulence is evident in the virulent nature of popp 1 mutant in resistant petunia line St 40 , and in the restoration of avirulence following genetic complementation. Results in western blot using bacterial cells of wild type and the mutants showed that PopP1 is secreted by $R$. solanacearum using TTSS. But unlike PopA, PopB, and PopC TTSS-dependent effectors, PopPI gene does not colocalized in the vicinity of the hrp gene cluster on the megaplasmid but rather on the bacterial chromosome. A detailed information was reported by Lavie et al. 2002.

\section{AvrPphB}

P. syringae pv. Phaseolicola secrets AvrpPhB, an avirulence protein responsible for initiating halo-blight disease in bean (Jenner et al. 1991). AvrPphB protein is a cysteine protease member of YopT family, capable of autoproteolytic cleavage of an AvrpPHB precursor for eliciting HR (Shao et al. 2002). Shao et al. (2002) demonstrated that proteolytic inactive mutants of $A v r P p h B$ (induced mutation in the $A v r P p h B$ catalytic triad C98S, $\mathrm{H} 212 \mathrm{~A}$, and D227A) are incapable of inducing HR in Arabidopsis suggesting that proteolytic activity is needed for $A v r P p h B$ to induce HR. P. syringae strains carrying $A v r P p h B$ induce an HR when inoculated into Arabidopsis plants carrying the cognate $\mathrm{R}$ gene $R P S 5$, and also, it induces HR when transiently expressed in tobacco leaves (Simonich and Innes 1995). Since HR cannot proceed without AvrPphB, it was proposed that RPS5 is activated after it binds to a peptide released from the substrate of AvrPphB (Shao et al. 2002). PBS1 kinase was considered as the potential substrate interacting with $\mathrm{AvrPphB}$, as deletion of the PBS1 from Arabidopsis makes AvrPphB unrecognizable by RPS5 (Swiderski and Innes 2001). Further, AvrPphB was shown to cleave PBS1 independent of RAR1 and RPS5 in Arabidopsis (Shao et al. 2003). Specifically, this team of investigators identified the cleavage sites in PBS1 at a position composed of stretch of three amino acids immediately preceding the AvrPphB autocleavage site after $\mathrm{K}^{243}$. A detailed information was reported by Shao et al. 2003.

\section{AvrRpt2}

More recently, apart from the two sequence-unrelated TTSS proteins of $P$. syringae targeting Arabidopsis protein RIN4 (Mackey et al. 2002), a third sequence-unrelated effector called AvrRpt2 was found to inhibit RIN4 inside the host cell by inducing post transcriptional elimination (Mackey et al. 2003). AvrRpt2, a Pseudomonas syringae pv. tomato (Pst) TTSS effector protein, is thought to elicit an immunity response in RPS2 -expressing Arabidopsis (KunKel et al. 1993). Translocation of AvrRpt2 to the cell during infection results in its cleavage at amino acids 71 and 72 to liberate a stable terminal $21 \mathrm{kDa}$ product for RPS2 binding (Mudgett and Staskawicz 1999). Hotson and Mudgett (2004) demonstrate that activation of the RPS2 R protein solely depends on the AvrRpt2-mediated removal of RIN4 (Fig. 1D). In a proposed model by Mackey et al. (2003), inhibiting RIN4 disappearance prevents RPS2 activation, and the lethality associated with RIN4 disruption requires RPS2. Even at a barely detectable RIN4 levels, plants still initiate normal RPS2-dependent response to AvrRpt 2 implying that only by total elimination of RIN4 does AvrRpt2 activate RPS2 (Mackey et al. 2002). Moreover, elaboration of $A v r R p t 2$ interference mechanism was depicted in the physical interactions of AvrRpt2, RIN4, and RPM1 at the plasma membrane (Hotson and Mudgett 2004). A detailed information was reported by Mackey et al. 2002.

\section{Nucleocytoplasmic shuttling of PLCP during interaction}

Recent studies on subcellular localization of key resistance components situate nucleus at the forefront of the hostpathogen interface (Rivas 2012). With the accumulating evidence highlighting the significance of nuclear localization of effectors and key host resistance components for disease resistance in plants, nuclear dynamics is taken as a key event essential for plant defense (Deslandes and Rivas 
2011). Some of the dynamic cellular processes that occur with defense response include plant cell trafficking, cytoskeleton reorganization, organelle positioning, and cytoplasmic-nuclear transport and partitioning (Lipka and Panstruga 2005; Robatzek 2007; Shen et al. 2007; Shen and Schulze-Lefert 2007; Wiermer et al. 2007; Bernoux et al. 2008). Among the interesting consequences of nuclear translocation of effectors is the subcellular localization of their cognate R proteins (Deslandes et al. 2003; Shen et al. 2007). Having been implicated in different pathosystems, PLCPs were shown to be an important target of microbial effectors resulting in nucleocytoplasmic trafficking during interaction.

PopP2 from $R$. solanacearum presents a nuclear localization signal (NLS) that is required for its nuclear translocation (Deslandes et al. 2003). As previously reported, direct translocation of PopP2 effector to the nucleus of host plant cells promotes nuclear accumulation of RRS1-R, an atypical $\mathrm{R}$ protein which confers resistance to $R$. solanacearum, possibly by preventing its proteasomal degradation (Deslandes et al. 2003; Rivas 2012). RRS1-R has been shown to interact with its cognate effector PopP2 in yeast cells (Deslandes and Rivas 2011). PopP2 interaction with $R R S 1-R$ was proposed to regulate defense-related gene expression either directly via the RRS1-R WKRY domain or through the action of additional plant TFs (Deslandes et al. 2003; Tasset et al. 2010). In their extensive study, Bernoux et al. (2008) identified and demonstrated additional important component of PopP2-RRS1-R mediated resistance. By performing yeast-two hybrid screening using PopP2 as bait, a cysteine protease $R D 19$ was identified among the targets. Subsequent experiments assert that $R D 19$ is a crucial host factor for PopP2-triggered RRS1-R-mediated resistance as exemplified in $r d 19$ loss of function and genetic complementation studies. As detailed by Bernoux et al. (2008), RD19 localizes to the lytic vacuole and becomes active after proteolysis (Paris et al. 1996). Interestingly, when co-expressed in $N$. benthamiana, RD19 was shown to shuttle to the nucleus with PopP2. Further, the FLIM analysis in living cells confirmed a physical interaction between PopP2 and RD19 in the nucleus (Fig. 1A). Intriguingly, there was no interaction detected between Rd19 and RRS1-R. Also, PopP2 and RD19 association was not affected in the presence of RRS1-R. Since RD19 is required for Arabidopsis resistance to Ralstonia, it was proposed that the RD19-PopP2 nuclear complex is the one required for activation of the plant resistance response (Rivas 2012). How RD19 exactly activates resistance response remains unknown but Bernoux et al. (2008) theorized that the nuclear RD19 may function as transcriptional activator or competes with RRS1-R for similar or overlapping cis-elements in the promoters of defenserelated genes. Unlike PopP2, RD19 lacks consensus NLS that would have allow its nuclear trafficking (Rivas 2012). Possibly, the vacuolar membrane collapse during the elicitor-induced membrane permeabilization releasing RD19 from vacuole-associated compartments into the cytoplasm where they may become available for SUMOylation (Matarasso et al. 2005; Bernoux et al. 2008), a process which generate signals required for their nuclear translocation (Rivas 2012). A detailed information was reported by Bernoux et al. 2003.

\section{Coevolutionary arms race between plants PLCP and effectors}

Translocation mechanisms for pathogen effectors are continuously evolving as means of manipulating the host cytoplasm and suppression of host immunity (Jones and Dangl 2006). Selection pressure on host enzyme yields variant residues at the interaction surface of the enzymeinhibitor interactions (Misas-Villamil and van der Hoorn 2008). An emerging concept in antagonistic host-pathogen interactions states that to escape manipulation, effector/ avirulence targets are subject to diversifying selection (Hougenhout et al. 2009). Shabab et al. (2008) reported that tomato plants create a harmful proteolytic apoplast through secretion of PLCPs during defense to halt pathogen build up. In particular, tomato apoplast is populated with remarkable diverse PLCP activities by seven PLCPs that fall into four different subfamilies, two of which are PIP1 and RCR3. However, Avr2 effector inhibits all apoplastic PLCP activities. Shabab et al. (2008) further demonstrate the fate of these two PLCPs (PIPI and RCR3) upon inhibition by $A V R 2$. As indicated in their findings, PIPI and $R C R 3$ are less conserved compared with the other proteases. Sequencing of the region that encodes protease 
domain of eight wild tomato relatives revealed variant nucleotides in the seven PLCPs, with PIPI and RCR3 containing variant codons that cause nonsimilar amino acid substitutions. This means that $P I P 1$ and $R C R 3$ are under diversifying selection resulting in variant residues around the substrate binding groove of the protease, deemed to match the coevolving substrates (Shabab et al. 2008). Diversifying selection at interaction surfaces between inhibitors and their substrates are common in plant-pathogen interactions (Misas-Villamil and van der Hoorn 2008). A detailed information was reported by Shabab et al. 2008.

In the study performed by Kaschani et al. (2010), C14 was tagged as a new common target of EPIC1 and EPIC2B, the two apoplastic, cystatin-like proteins secreted by potato typified by a carboxyl-terminal granulin domain. These EPICs proteins strongly inhibit $\mathrm{C} 14$, as significant inhibition assays proceed even at lower EPIC concentrations and at wide $\mathrm{pH}$ value-range (Kaschani et al. 2010). C14 is a highly conserved cysteine protease in the plant kingdom characterized by a unique, $\mathrm{C}$-terminal granulin-like domain that shares homology with animal growth hormones (Bateman and Bennett 1998). In tomato, C14 was reported to undergo conservative selection which is evident in the resultant few variant codons causing change in the encoded amino acid (Shabab et al. 2008). Possibly, this could be due to the fact that wild tomato is not the natural host of $P$. infestans (Debener et al. 1990). This prompted the investigators to examine for natural variation of $\mathrm{C} 14$ in the natural hosts of $P$. infestans in the three wild potato species including $S$. demissum, S. verrucosum, and S. stoliniferum (Debener et al. 1990; Grünwald and Flier 2005; Kaschani et al. 2010). As demonstrated by Kaschani et al. (2010), a total of six new $\mathrm{C} 14$ alleles were identified in addition to the $\mathrm{C} 14$ allele of cultivated potato deposited in the National Center for Biotechnology Information database. Further, phylogenetic analysis revealed the difference of potato and tomato $\mathrm{C} 14$ alleles both at the protein and nucleotide levels marked by expanded branch lengths of potato than in tomato indicating most nucleotide polymorphisms in potato C14s cause amino acid changes (Kaschani et al. 2010). Moreover, as shown using phylogenetic analysis of potato $\mathrm{C} 14$ sequences (Yang 2007), there is $95 \%$ probability that potato $\mathrm{C} 14$ is under diversifying selection due to strong selective pressure from $P$. infestans. A detailed information was reported by Kaschani et al. 2010.

\section{General inference}

Despite the overwhelming number of cysteine proteases in plants, only a handful were successfully investigated. In Arabidopsis alone, functions for only a few of the more than 550 peptidases (Rawlings et al. 2014) have been studied genetically (Adam and Clarke 2002; Beers et al. 2004; van der Hoorn et al. 2004). Introduction of protease activity profiling has been very instrumental in assigning functions for proteases. The current status of cysteine protease research in plant disease immunity features its diverse and overlapping role in basal and effector-triggered immunity. Among the findings, PLCPs are inferred as important target of pathogen effector guarded by other $\mathrm{R}$ genes for defense. An intriguing incidence of nucleocytoplasmic trafficking of a few members such as $R D 19$ provides a notion that PCLPs are involved in the crucial transcriptional regulation of defense-related genes in the host. Yet, our understanding regarding how PLCPs shuttle to the nucleus remains obscure. Another exciting inference is the effect of strong selection pressure in inducing variant codons which leads to coevolutionary arms race between $\mathrm{R}$ gene and effector under natural pathosystem.

The limited current data insufficiently benchmark our basic understanding on how PLCP activities modulate host-pathogen interaction. Although most of the demonstrated cysteine proteases are closely related, yet they exhibit different roles thus prompting us to explore more PLCP members in many other pathosytems, and extricate further mechanism of defense regulation in the host cell.

\section{ACKNOWLEDGMENT}

This work was supported by the research grant of the Chungbuk National University in 2012, by Golden Seed Project, Ministry of Agriculture, Food and Rural Affairs (MAFRA), and by a grant from the Next-generation BioGreen 21 Program (Project No. PJ008529), Rural Development Administration, Republic of Korea. 


\section{REFERENCES}

Adam Z, Clarke AK. 2002. Cutting edge of chloroplast proteolysis. Trends Plant Sci. 7: 451-456.

Alfano JR, Collmer A. 2004. Type III secretion system effector proteins: double agents in bacterial disease and plant defense. Annu. Rev. Phytopathol. 42: 385-414.

Axtell MJ, Chisholm ST, Dahlbeck D, Staskawicz BJ. 2003. Genetic and molecular evidence that the Pseudomonas syringae type III effector protein AvrRpt2 is a cysteine protease. Mol. Microbiol. 49: 1537-1546.

Barrett AJ, Rawlings ND. 2001. Evolutionary lines of Cysteine peptidases. Biol. Chem. 382: 727-733.

Bateman A, Bennett HPJ. 1998. Granulins: the structure and function of an emerging family of growth factors. J. Endocrinol. 158: 145-151.

Beers EP, Jones AM, Dickerman AW. 2004. The S8 serine, $\mathrm{C} 1 \mathrm{~A}$ cysteine and $\mathrm{A} 1$ aspartic protease families in Arabidopsis. Phytochemistry 65: 43-58.

Bernoux M, Timmers T, Jauneau A, Briere C, de Wit PJ, Marco Y, Deslandes L. 2008. RD19, an Arabidopsis cysteine protease required for RRS1-R-mediated resistance, is relocalized to the nucleus by the Ralstonia solanacearum PopP2 effector. Plant Cell 20: 2252-2264.

Birch PRJ, Whisson S. 2001. Phytophthora infestans enters the genomics era. Mol. Plant Pathol. 2: 257-263.

Büttner D, Bonas U. 2006. Who comes first? How plant pathogenic bacteria orchestrate type III secretion. Curr. Opin. Microbiol. 9: 193-200.

Carrington JC, Herndon KL. 1992. Characterization of the potyviral HC-Pro autoproteolytic cleavage site. Virology 187: 308-315.

Coaker G, Falick A, Staskawicz B. 2005. Activation of a phytopathogenic bacterial effector protein by a eukaryotic cyclophilin. Science 308: 548-550.

Coates ME, Beynon JL. 2010. Hyaloperonospora arabidopsidis as a pathogen model. Annu. Rev. Phytopathol. 48: 329345 .

Cornelis G, Van Gijsegem F. 2000. Assembly and function of type III secretory systems. Annu Rev Microbiol. 54: 735-74.

Dangl JL, Jones JDG. 2001. Plant pathogens and integrated defence responses to infection. Nature 411: 826-833.

Debener T, Salamini F, Gebhardt C. 1990. Phylogeny of wild and cultivated Solanum species based on nuclear restriction fragment length polymorphisms (RFLPs). Theor. Appl. Genet. 79: 360-368.

Deslandes L, Olivier J, Peeters N, Feng DX, Khounlotham M, Boucher C, Somssich I, Genin S, Marco Y. 2003. Physical interaction between RRS1-R, a protein conferring resistance to bacterial wilt, and PopP2, a type III effector targeted to the plant nucleus. Proc. Natl. Acad. Sci. USA 100: 8024-8029.

Deslandes L, Rivas S. 2011. The plant cell nucleus: a true arena for the fight between plants and pathogens. Plant Signal. Behav. 6: 42-48

Deslandes L, Olivier J, Theulières F, Hirsch J, Feng DX, Bittner-Eddy P, Beynon J, Marco Y. 2002. Resistance to Ralstonia solanacearum is conferred by the recessive RRS1-R gene, a member of a novel family of resistance genes. Proc. Natl. Acad. Sci. USA 99: 2404-2409.

De Wit PJGM, Buurlage MB, Hammond KE. 1986. The occurrence of host, pathogen and interaction-specific proteins in the apoplast of Cladosporium fulvum (syn. Fulvia fulva) infected tomato leaves. Physiol. Mol. Plant Pathol. 29: 159-172.

Dixon MS, Golstein C, Thomas CM, van der Biezen EA, Jones JDG. 2000. Genetic complexity of pathogen perception by plants; the example of Rcr3, a tomato gene required specifically by cf-2. PNAS 97: 8807-8814.

Dixon MS, Jones DA, Keddie JS, Thomas CM, Harrison K, Jones JD. 1996. The tomato Cf-2 disease resistance locus comprises two functional genes encoding leucine-rich repeat proteins. Cell 84: 451-59.

Drenth J, Jansonius JN, Koekoek R, Wolthers BG. 1971. The crystal structure of papain C. I. Two dimensional fourier synthesis. Adv. Protein Chem. 25: 79-115.

Eulgem T, Somssich IE. 2007. Networks of WRKY transcription factors in defence signalling. Curr. Opin. Plant Biol. 10: 366-371.

Gilroy EM, Hein I, van der Hoorn RAL, Boevink PC, Venter E, McLellan H, Kaffarnik F, Hrubikova K, Shaw J, Holeva M, Lopez EC, Borras-Hidalgo O, Pritchard L, Loake GJ, Lacomme C, Birch PRJ. 2007. Involvement of cathepsin B in the plant disease resistance hypersensitive response. Plant J. 52: 1-13.

Golubtsov A, Kaariainen L, Caldentey J. 2006. Characterization of the cysteine protease domain of Semliki Forest virus replicase protein nsP2 by in vitro mutagenesis. FEBS Lett. 580: 1502-1508. 
Grudkowska M, Zagdanska B. 2004. Multifunctional role of plant cysteine proteinases. Acta Biochim. Pol. 51: 609-624.

Grünwald NJ, Flier WG. 2005. The biology of Phytophthora infestans at its center of origin. Annu. Rev. Phytopathol. 43: 171-190.

Hayward AC. 1991. Biology and epidemiology of bacterial wilt caused by Pseudomonas solanacearum. Annu. Rev. Phytopathol. 29: 65-87.

He SY, Nomura K, Whittam TS. 2004. Type III protein secretion mechanism in mammalian and plant pathogens. Biochin. Bipphys. Acta 1694: 181-206.

Hotson A, Mudgett MB. 2004. Cysteine proteases in phytopathogenic bacteria: Identification of plant targets and activation of innate immunity. Curr. Opin. Plant Biol. 7: 384-390.

Hougenhout SA, van der Hoorn RAL, Terauchi R, Kamoun S. 2009. Emerging concepts in effector biology of plant associated organisms. Mol. Plant-Microbe Interact. 22: 115-122.

Jenner C, Hitchin E, Mansfield J, Walters K, Betteridge P, Teverson D, Taylor J. 1991. Gene-for-gene interactions between Pseudomonas syringae pv. phaseolicola and Phaseolus. Mol. Plant Microbe Interact. 4: 553-562.

Jones JDG, Dangl JL. 2006. The plant immune system. Nature 444: 323-329.

Kaschani F, Shabab M, Bozkurt T, Shindo T, Schornack, Gu C, Ilyas M, Win J, Kamoun S, van der Hoorn RA. 2010. An effector-targeted protease contributes to defense against Phytophthora infestans and is under diversifying selection in natural hosts. Plant physiol. 154: 1794-804. DOI: $10.1104 /$ pp.110.158030.

Keen N. 1990. Gene-for-gene complementarity in plantpathogen interactions. Annu. Rev. Genet. 24: 447-463.

Krüger J, Thomas CM, Golstein C, Dixon MS, Smoker M, Tang S, Mulder L, Jones JDG. 2002. A tomato Cysteine protease required for $\mathrm{Cf}$-2-dependent disease resistance and suppression of autonecrosis. Science 296: 744-747.

Kunkel BN, Bent AF, Dahlbeck D, Innes RW, Staskawicz BJ. 1993. RPS2, an Arabidopsis disease resistance locus specifying recognition of Pseudomonas syringae strains expressing the avirulence gene avrRpt2. Plant Cell 5: 865-875.

Lam E, Naohiro K, Lawton M. 2001. Programmed cell death, mitochondria and the plant Hypersensitive response. Nature 411: 848-853.
Lavie M, Shillington E, Eguiluz C, Grimsley N, Boucher C. 2002. PopP1, a new member of the YopJ/AvrRxv family of type III effector proteins, acts as a host-specificity factor and modulates aggressiveness of Ralstonia solanacearum. Mol. Plant Microbe Interact. 15: 1058-1068.

Lindgren PB, Peet RC, Panopoulos NJ. 1986. Gene-cluster of Pseudomonas syringae pv. phaseolicola controls pathogenicity of bean plants and hypersensitivity on nonhost plants. J. Bacteriol. 168: 512-522.

Lipka V, Panstruga R. 2005. Dynamic cellular responses in plant-microbe interactions. Curr. Opin. Plant Biol. 8: 625-631.

Lopez-Solanilla E, Bronstein PA, Schneider AR, Collmer A. 2004. HopPtoN is a Pseudomonas syringae Hrp (type III secretion system) cysteine protease effector that suppresses pathogen-induced necrosis associated with both compatible and incompatible plant interactions. Mol. Microbiol. 54: 353-365.

Lozano-Torres JL, Wilbers RHP, Gawronski P, Boshoven JC, Finkers-Tomczak A, Cordewener JHG, Americab AHP, Overmarsa HA, Van 't Kloosterc JW, Baranowskid L, Sobczakd M, Ilyase M, van der Hoorne RAL, Schotsa A, de Wit PGJM, Bakkera J, Goversea A, Smanta G. 2012. Dual disease resistance mediated by the immune receptor Cf-2 in tomato requires a common virulence target of a fungus and a nematode. PNAS doi/10.1073/pnas.1202 867109.

Mackey D, Belkhadir Y, Alonso JM, Ecker JR, Dangl JL. 2003. Arabidopsis RIN4 is a target of the type III virulence effector AvrRpt 2 and modulates RPS2-mediated resistance. Cell 112: 379-389.

Mackey D, Holt BF, Wiig A, Dangl JL. 2002. RIN4 interacts with Pseudomonas syringae Type III effector molecules and is required for RPM1-mediated disease resistance in Arabidopsis. Cell 108: 743-754.

Matarasso N, Schuster S, Avni A. 2005. A novel plant Cysteine protease has a dual function as a regulator of 1-aminocyclopropane- 1-carboxylic acid synthase gene expression. Plant Cell 17: 1205-1216.

Misas-Villamil JC, van der Hoorn RAL. 2008. Enzyme inhibitor interactions at the plant-pathogen interface. Curr. Opin. Plant Biol. 11: 380-388.

Mudgett MB, Staskawicz BJ. 1999. Characterization of the Pseudomonas syringae pv. tomato AvrRpt2 protein: demonstration of secretion and processing during bacterial 
pathogenesis. Mol. Microbiol. 32: 927-941.

Orth K. 2002. Function of the Yersinia effector YopJ. Curr. Opin. Microbiol. 5: 38-43.

Orth K, Xu Z, Mudgett MB, Bao ZQ, Palmer LE, Bliska JB, Mangel W, Staskawicz B, Dixon JE. 2000. Disruption of signaling by Yersinia effector YopJ, a ubiquitin-like protein protease. Science 290: 1594-1597.

Paris N, Stanley CM, Jones RL, Rogers JC. 1996. Plant cells contain two functionally distinct vacuolar compartments. Cell 85: 563-572.

Powers JC, Asgian JL, Ekici OD, James KE. 2002. Irreversible inhibitors of serine, cysteine, and threonine proteases. Chem. Rev. 102: 4639-4750.

Rawlings ND, Morton FR, Barrett AJ. 2006. MEROPS: the peptidase database. Nucleic Acids Res. 34: 270-72.

Rawlings ND, Barrett AJ, Bateman A. 2010. MEROPS: the peptidase database. Nucleic Acids Res. 38: D227-D233.

Rawlings ND, Waller M, Barrett AJ, Bateman A. 2014. MEROPS: the databse of proteolytic enzymes, their substrates and inhibitors. Nucleic Acids Res. 42: D503D509.

Ristaino JB. 2002. Tracking historic migrations of the Irish potato famine pathogen, Phytophthora infestans. Microbes Infect. 4: 1369-1377.

Rivas S. 2012. Nuclear dynamics during plant innate immunity. Plant Physiol. 158: 87-94.

Robatzek S. 2007. Vesicle trafficking in plant immune responses. Cell Microbiol. 9: 1-8.

Rooney HC, Van't Klooster JW, van der Hoorn RAL, Joosten MHAJ, Jones JDG, de Wit PJGM. 2005. Cladosporium Avr2 inhibits tomato Rcr3 protease required for $\mathrm{Cf}-2$ dependent disease resistance. Science 308: 1783-1786.

Shabab M, Shindo T, Gu C, Kaschani F, Pansuriya T, Chintha R, Harzen A, Colby T, Kamoun S, van der Hoorn RAL. 2008. Fungal effector protein AVR2 targets diversifying defense-related cys proteases of tomato. Plant Cell 20: 1169-1183.

Shao F, Dixon JE. 2004. YopT protease and its homologs. In Handbook of Proteolytic Enzymes, 2 ed. p.1257-1259, Elsevier, London.

Shao F, Golstein C, Ade J, Stoutemyer M, Dixon JE, Innes RW. 2003. Cleavage of Arabidopsis PBS1 by a bacterial type III effector. Science 301: 1230-1233.

Shao F, Merritt PM, Bao Z, Innes RW, Dixon JE. 2002. A Yersinia effector and a Pseudomonas avirulence protein define a family of cyetsien proteases functioning in bacterial pathogenesis. Cell 109: 575-588.

Shen QH, Saijo Y, Mauch S, Biskup C, Bieri S, Keller B, Seki H, Ulker B, Somssich IE, Schulze-Lefert P. 2007. Nuclear activity of MLA immune receptors links isolatespecific and basal disease-resistance responses. Science 315: 1098-1103.

Shen QH, Schulze-Lefert P. 2007. Rumble in the nuclear jungle: Compartmentalization, trafficking, and nuclear action of plant immune receptors. EMBO J. 26: 4293 4301.

Shindo T, Misas-Villamil JC, Horger AC, Song J, van der Hoorn RAL. 2012. A role in immunity for Arabidopsis cysteine protease RD21, the ortholog of the tomato immune protease C14. PLoS ONE 7: e29317. doi:10. 1371/journal.pone.0029317.

Shindo T, van der Hoorn RAL. 2008. Papain-like cysteine proteases: key players at molecular battlefields employed by both plants and their invaders. Mol. Plant Pathol. 9: 119-125.

Simonich MT, Innes RW. 1995. A disease resistance gene in Arabidopsis with specificity for the avrPph3 gene of Pseudomonas syringae pv. phaseolicola. Mol. Plant Microbe Interact. 8: 637-640.

Smart CD, Fry WE. 2001. Invasions by the late blight pathogen: renewed sex and enhanced fitness. Biol Invasions 3: 235-243

Solomon M, Belenghi B, Delledonne M, Menachem E, Levine A. 1999. The involvement of cysteine proteases and protease inhibitor genes in the regulation of programmed cell death in plants. Plant Cell 11: 431-443.

Swiderski MR, Innes RW. 2001. The Arabidopsis PBS1 re sistance gene encodes a member of a novel protein kinase subfamily. Plant J. 26: 101-112.

Tasset C, Bernoux M, Jauneau A, Pouzet C, Brie're C, Kieffer-Jacquinod S, Rivas S, Marco Y, Deslandes L. 2010. Autoacetylation of the Ralstonia solanacearum effector PopP2 targets a lysine residue essential for RRS1-R-mediated immunity in Arabidopsis. PLoS Pathog. 6:e1001202.

Taylor MA, Baker KC, Briggs GS, Connerton IF, Cummings NJ, Pratt KA, Revell DF, Freedman RB, Goodenough PW. 1995. Recombinant pro-regions from papain and papaya proteinase IV-are selective high affinity inhibitors of the mature papaya enzymes. Protein Eng. 8: 59-62. 
Tian M, Win J, Song J, van der Hoorn RAL, van der Knaap E, Kamoun S. 2007. A Phytophthora infestans cystatin-like protein targets a novel tomato papain-like apoplastic protease. Plant Physiol. 143, 364-377.

van der Biezen EA, Jones JDG. 1998. Plant disease-resistance proteins and the gene-for-gene concept. Trends Biochem. Sci. 23: 454-456.

van der Hoorn RAL. 2008. Plant proteases: From phenotypes to molecular mechanisms. Annu. Rev. Plant Biol. 59: 191-223.

van der Hoorn RAL, Leeuwenburgh MA, Bogyo M, Joosten MHAJ, Peck SC. 2004. Activity profiling of papain-like cysteine proteases in plants. Plant physiol. 135: 11701178 . van der Knaap E, Tanksley SD. 2001. Identification and characterization of a novel locus controlling early fruit development in tomato. Theor. Appl. Genet. 103: 353358.

Wiermer M, Palma K, Zhang Y, Li X. 2007. Should I stay or should I go? Nucleocytoplasmic trafficking in plant innate immunity. Cell. Microbiol. 9: 1880-1890.

Yang Z. 2007. PAML 4: phylogenetic analysis by maximum likelihood. Mol. Biol. Evol. 24: 1586-1591.

Zhao Y, Thilmony R, Bender CL, Schaller A, He SY, Howe GA. 2003.Virulence systems of Pseudomonas syringae pv. tomato promote bacterial speck disease in tomato by targeting the jasmonate signaling pathway. Plant J. 36: 485-499. 